\title{
Levothyroxine intramuscular administration-Case report and Review of literature
}

\author{
Nasser Mikhail* \\ Department of Medicine, OliveView-UCLA Medical Center, Sylmar, CA 91342, USA
}

\begin{abstract}
Background: Limited data exist regarding safety and efficacy of levothyroxine given intramuscularly.

Methods: To report a patient with thyroid cancer invading the trachea, with subsequent tracheostomy, gastrostomy tube feeding, and subtotal thyroidectomy complicated by severe hypoparathyroidism. All previous cases in the literature who received intramuscular levothyroxine were also described.

Results: In our patient, levothyroxine administration in gastrostomy tube failed to suppress thyrotropin stimulating factor (TSH) levels, most likely due to concomitant administration of calcium and food constituents. Patient's thyroid function stabilized few days after switching from enteral to intramuscular levothyroxine in a maintenance dose of $200 \mathrm{mcg}$ daily. Review of literature reveals 7 patients who were treated with intramuscular levothyroxine, mostly once a week. Main causes of treatment with intramuscular thyroxine were non-compliance and gastrointestinal (GI) malabsorption. Adverse effects reported were transient tachycardia in one patient and self-limited left side weakness in another patient.
\end{abstract}

Conclusions: Available data suggest that intramuscular administration of levothyroxine is effective, generally safe, and could be a viable alternative to oral levothyroxine in non-compliant patients or those with GI malabsorption.

\section{Introduction}

Levothyroxine is mainly given through the oral route or GI tube feeding. A levothyroxine solution $(100 \mathrm{mcg} / \mathrm{ml})$ is also available for intravenous administration [1]. The latter formulation is approved by the Federal Drug Administration (FDA) since 1969 for use in cases of myxedema coma [1]. Meanwhile, little is known about the use of intramuscular levothyroxine, which is currently not approved by the FDA. In the latest guidelines on treatment of hypothyroidism prepared by the American Thyroid Association, it was mentioned: "Parenteral levothyroxine therapy does not appear to have been rigorously studied..., no trials of such therapy were identified" [2]. In fact, in the previous guidelines, no recommendations were specifically provided for intramuscular levothyroxine [2]. Review of literature revealed only 7 patients who received levothyroxine intramuscularly. The author reports here an $8^{\text {th }}$ case, and summarizes available data related to this uncommon form of levothyroxine administration.

\section{Case report}

The patient is 40 year-old morbidly obese (weight $131 \mathrm{~kg}$ ) woman with poorly differentiated thyroid cancer invasive of the trachea that underwent subtotal thyroidectomy followed by tracheostomy and gastrostomy tube insertion for feeding. Surgery was complicated by severe hypoparathyroidism requiring large doses of calcium. The latter consisted of carbonate/vitamin D $600 \mathrm{mg} / 400$ IU tablet, 2 tablets q6 h, calcium acetate $667 \mathrm{mg}$ capsule, 4 capsules $(2,668 \mathrm{mg}) \mathrm{q} 6 \mathrm{~h}$ through the gastrostomy tube. Initially, intravenous levothyroxine was started in a dose $150 \mathrm{mcg} / \mathrm{d}$ for few days then switched to levothyroxine tablet which was crushed and introduced in the gastrostomy tube in a dose of $225 \mathrm{mcg} /$ day. Yet, levothyroxine administered in gastrostomy tube did not normalize thyroid function despite escalation of doses up to
$300 \mathrm{mcg} /$ day. Thus, TSH levels were $12.2 \mathrm{uIU} / \mathrm{ml}(\mathrm{N}=0.35-4.94 \mathrm{uIU} /$ $\mathrm{ml})$, and free thyroxine (T4) levels were $1.11 \mathrm{ng} / \mathrm{dl}(\mathrm{N}=0.70-1.48 \mathrm{ng} /$ dl). Subsequently, enteral levothyroxine was switched to intramuscular levothyroxine in a starting dose of $250 \mathrm{mcg} / \mathrm{d}$, then few days later decreased to a maintenance dose of $200 \mathrm{mcg} / \mathrm{d}(1.5 \mathrm{mcg} / \mathrm{kg} / \mathrm{d})$. Over the next 15 days after switching to intramuscular levothyroxine, TSH levels were $0.167 \mathrm{uIU} / \mathrm{ml}$, almost at goal for patients with invasive thyroid cancer $(\mathrm{TSH}<0.1 \mathrm{uIU} / \mathrm{ml})$ [3], and free T4 levels were high normal at $1.46 \mathrm{ng} / \mathrm{dl}$.

\section{Problems of levothyroxine administered through gastrostomy tube}

\section{Decreased absorption of levothyroxine by calcium}

In 1998, Schneyer reported development of hypothyroidism in 3 women with thyroid cancer on levothyroxine suppressive therapy after taking levothyroxine and calcium carbonate concomitantly [4]. In one patient, TSH was corrected 3 weeks after stopping calcium carbonate. In the 2 remaining patients, normal thyroid function was restored when they took levothyroxine in the morning and calcium carbonate after lunch and dinner [4]. In healthy volunteers, Singh, et al. showed that calcium carbonate significantly decreased the absorption of levothyroxine over the 24 hours following the simultaneous intake of both drugs [5]. In

${ }^{\star}$ Correspondence to: Nasser Mikhail, Department of Medicine, OliveViewUCLA Medical Center, Sylmar, CA 91342, USA, E-mail: nmikhail@dhs. lacounty.gov

Key words: Levothyroxine, intramuscular, tube feeding, calcium, absorption, safety Received: February 19, 2020; Accepted: February 25, 2020; Published: February 28,2020 
20 patients with stable primary hypothyroidism, the same researchers have shown that $20 \%$ of such patients developed mild hypothyroidism (highest TSH was $7.8 \mathrm{uIU} / \mathrm{ml}$ ) when taking levothyroxine with calcium carbonate [6]. Furthermore, this levothyroxine-calcium interaction extends to other calcium preparations. Thus, Zamfirescu and Carlson demonstrated that calcium acetate, calcium citrate, and calcium carbonate reduced the absorption of levothyroxine by $20-25 \%$ over a 6 h-hour period [7]. Cow milk also interferes with levothyroxine absorption, presumably due to its calcium content [8]. The mechanism of reduction of levothyroxine bioavailability by calcium is believed to be adsorption of levothyroxine to calcium in an acidic $\mathrm{pH}$ [6]. In our patient, we believe failure to achieve normal thyroid function was in part attributed to reduction of levothyroxine absorption in the gut by the high doses of calcium carbonate and acetate given every 6 hours. Some authors recommend holding calcium supplements for 4 hours after levothyroxine. We did not follow this regimen for the following reasons. First, this recommendation is based on expert opinion and not supported by data [1]. Second, as mentioned above, Singh et showed reduced levothyroxine absorption over $24 \mathrm{~h}$ after simultaneous intake of calcium [5]. In addition, in the studies of Zamfirescu and Carlson, different calcium formulations interfered with levothyroxine for a least 6 hours [7]. Third, we were concerned that interruption of calcium carbonate and acetate may result in development of hypocalcemic symptoms.

\section{Decreased absorption of levothyroxine by feeding constituents}

Absorption of levothyroxine takes place in the jejunum and ileum [1,9]. Acidic gastric $\mathrm{pH}$, as occurs in fasting condition, may be important for subsequent intestinal absorption $[1,6,9]$. Thus, food is expected to decrease absorption of levothyroxine [1]. In healthy subjects, Wenzel and Kirschsieper have shown that levothyroxine absorption with food was $64 \%$ compared with $80 \%$ in the fasting state [10]. Therefore, it is recommended to take levothyroxine at least 30 minutes in the morning before breakfast $[1,11]$. With respect to patients dependent on tube feeding like ours, Dickerson, et al. showed that more than half of patients ( 9 of 13 patients) receiving concurrent levothyroxine and continuous tube feeding developed subclinical or overt hypothyroidism within 2-3 weeks [12]. Holding tube feeding 1 hour before and after levothyroxine did not correct hypothyroidism in 2 of 3 patients [12]. It should be emphasized that, in the latter study, patients receiving nutrients that may interfere with levothyroxine absorption such as calcium, were excluded [12].

\section{Other problems associated with levothyroxine administration in tube feeding}

Mannesis, et al. examined the amount of levothyroxine that might be adsorbed by the gastrostomy tube [13]. Using radiolabeled levothyroxine, they found that there was minimal adsorption of levothyroxine during transit through feeding tubes [13]. The authors concluded that this effect was probably clinically insignificant [13]. Another problem that may potentially reduce the dose of levothyroxine is that a percentage of the drug, estimated to be approximately $10 \%$, may be lost during crushing, mixing and diluting levothyroxine tablet prior to its introduction in gastrostomy tube [13].

\section{Intramuscular administration of levothyroxine}

Review of the literature revealed only 7 patients who received levothyroxine through the intramuscular route [14-19] (Table 1). Major reasons for using intramuscular injection were lack of compliance with oral drug intake or isolated malabsorption of levothyroxine. As shown in Table 1, 5 of the 7 patients received levothyroxine once a week. We preferred to give intramuscular levothyroxine once a day in an attempt to avoid any possible fluctuations in plasma levothyroxine concentrations. This is particularly important in a patient with metastatic thyroid cancer in whom steady levels of thyroid hormones are essential for proper suppression of TSH. Unfortunately, pharmacokinetics and pharmacodynamics of intramuscular levothyroxine have not been studied. Therefore, the optimum frequency of its administration is unclear. Likewise, the optimum starting dose is unknown. In our patient with thyroid cancer who required TSH suppression, the optimum dose of intramuscular levothyroxine was approximately $1.5 \mathrm{mcg} / \mathrm{kg} / \mathrm{day}$. In patients with hypothyroidism who do not require TSH suppression, the optimum dose may be smaller e.g. $1.3 \mathrm{mcg} / \mathrm{kg} / \mathrm{d}$. In the elderly and patients with coronary artery disease, it is safer to start smaller doses of $25 \mathrm{mcg} / \mathrm{d}$, similar to the approach followed with oral levothyroxine [2]

\section{Safety of intramuscular administration of levothyroxine}

Overall, available studies suggest that intramuscular levothyroxine is safe. However, Peynirci, et al. reported transient left side loss of body strength that regressed within one week in a 32 year-old woman $24 \mathrm{~h}$ after intramuscular injection of levothyroxine in a dose of 1200 mcg [19]. In another report, Alba et described a 17 year-woman who developed palpitations one hour after receiving $200 \mathrm{mcg}$ of levothyroxine intramuscularly $(0.57 \mathrm{mcg} / \mathrm{kg} / \mathrm{day})$ [14]. Palpitations resolved after taking intravenous fluids in emergency department, and patient resumed intramuscular levothyroxine $200 \mathrm{mcg}$ weekly thereafter without adverse effects [14].

\section{Alternative ways of levothyroxine administration}

As mentioned above, a levothyroxine solution is approved for intravenous administration [1]. We used this intravenous formulation in a dose of $200 \mathrm{mcg} / \mathrm{d}$ for several days following thyroidectomy before

Table 1. Characteristics of patients who received intramuscular (IM) levothyroxine

\begin{tabular}{|c|c|c|c|}
\hline Reference & Patient's profile & Levothyroxine dosing regimen & Cause for using IM levothyroxine \\
\hline Alba, et al. [14] & 6 year-old female & $25 \mathrm{mcg}$ once a week gradually increased to $300 \mathrm{mcg}$ once a week & $\begin{array}{l}\text { Malabsorption of levothyroxine through } \\
\text { gastrostomy tube }\end{array}$ \\
\hline Alba, et al. [14] & 12 year-old fenale & $100 \mathrm{mcg}$ once a week increased gradually to $500 \mathrm{mcg}$ once a week & Non-compliance \\
\hline Alba, et al. [14] & 16 year-old female & $200 \mathrm{mcg}$ once weekly increased gradually to $500 \mathrm{mcg}$ once a week & Non-compliance \\
\hline Eledrisi, et al. $[15]$ & 41 year-old woman & $200 \mathrm{mcg} / \mathrm{d}$ & Non-compliance \\
\hline Anderson, et al. [16] & 18 year-old female & $500 \mathrm{mcg}$ once weekly increased gradually to $1000 \mathrm{mcg}$ once a week & Idiopathic levothyroxine malabsorption \\
\hline Gamboa, et al. [17] & 55 year-old male & $\begin{array}{l}200 \text { mcg twice a week increased over } 2 \text { months to } 400 \mathrm{mcg} \text { on Mondays and } 200 \mathrm{mcg} \\
\text { on Thursdays }\end{array}$ & Malabsorption due to intestinal subocclusion \\
\hline Taylor, et al. [18] & 82 year-old female & $\begin{array}{l}200 \mathrm{mcg} \text { once weekly increased to } 500 \mathrm{mcg} \text { once weekly after } 64 \text { days, then switched } \\
\text { back to oral levothyroxine after } 86 \text { days of IM levothyroxine }\end{array}$ & Myxedema coma due to non-compliance \\
\hline Peynirci, et al. [19] & 32 year-old female & $500 \mathrm{mcg}$ twice a week & Isolated (idiopathic) malabsorption \\
\hline Current report & 40 year-old female & $200 \mathrm{mcg} / \mathrm{d}(1.5 \mathrm{mcg} / \mathrm{kg} / \mathrm{d})$ & $\begin{array}{l}\text { Malabsorption of levothyroxine through } \\
\text { gastrostomy tube }\end{array}$ \\
\hline
\end{tabular}


insertion of gastrostomy tube. However, for long-term therapy, the intravenous route is impractical because it is quite invasive, and the intravenous access is prone for infections. Hence, we used the same solution of levothyroxine approved for the intravenous route to be given intramuscularly without any adverse effects. Levothyroxine was also given subcutaneously with success in a morbidly obese woman (weight $150 \mathrm{~kg}$, body mass index $53 \mathrm{~kg} / \mathrm{m}^{2}$ ) suffering from malabsorption in a dose of $400 \mathrm{mcg}$ every 4 days [20]. Main limitation of subcutaneous levothyroxine is the large volume $(500 \mathrm{mcg}$ corresponds to $10 \mathrm{ml})$, potentially causing pain at the injection site [20].

Pirola, et al. compared the traditional tablet form of levothyroxine with a new liquid formulation $(1.6 \mathrm{mcg} / \mathrm{kg} / \mathrm{d})$ introduced in nasogastric tube in 20 patients after undergoing laryngectomy and thyroidectomy [21]. After 21 days, patients randomized to the liquid form of levothyroxine had similar thyroid functions to those randomized to the tablet form [21]. The latter results occur despite holding tube feeding in the tablet group for $30 \mathrm{~min}$ before and after levothyroxine [21] These results suggest that the liquid formulation of levothyroxine may have less interaction with food constituents compared with the tablet form. Nevertheless, further studies of longer duration are needed to confirm this finding.

\section{Conclusions and current needs}

In hypothyroid patients refractory to treatment with oral or enteral levothyroxine, intramuscular levothyroxine appears to be a generally safe, practical and reliable alternative way of this drug administration. Unfortunately, data regarding intramuscular levothyroxine is scant. Investigations are urgently needed to study pharmacodynamics and pharmacokinetics of levothyroxine given through the intramuscular route. Likewise, well-designed clinical trials are required to compare intramuscular levothyroxine with other levothyroxine formulations in terms of safety, efficacy and patients' acceptance.

\section{Conflict of interest}

The author has no conflict of interest to declare.

\section{Acknowledgement}

The author is grateful to Mr Armen Carapetian for his professional librarian assistance.

\section{References}

1. Levothyroxine sodium for injection (2011) Prescribing information. APP Pharmaceuticals, Schauburg, IL 60173.

2. Jonklaas J, Bianco AC, Bauer AJ, Burman KD, Cappola AR, et al. (2014) Guidelines for the treatment of hypothyroidism. Prepared by the American Thyroid Association Task Force on thyroid hormone replacement. Thyroid 24: 1670-1750.
3. Haugen BH, Alexander EK, Bible KC, Doherty GM, Mandel SJ, et al. (2015) American Thyroid Association Management Guidelines for adult patients with thyroid nodules and differentiated thyroid cancer. Thyroid 26: 1-133.

4. Schneyer CR (1998) Calcium carbonate and reduced levothyroxine efficacy. JAMA 279: 750 .

5. Singh N, Weisler S, Hershman JM (2001) The acute effect of calcium carbonate on the intestinal absorption of levothyroxine. Thyroid 11: 967-971.

6. Singh N, Singh PN, Hershman JM (2000) Effect of calcium carbonate on the absorption of levothyroxine. JAMA 283: 2822-2825. [Crossref]

7. Zamfirescu I, Carslon HE (2011) Absorption of levothyroxine when coadministered with various calcium formulation. Thyroid 21: 483-486.

8. Chon DA, Reisman T, Weinreb JE (2018) Concurrent Milk Ingestion Decreases Absorption of Levothyroxine. Thyroid 28: 454-457. [Crossref]

9. Virili C, Antonelli A, Santaguida MG, Benvenga S, Centanni M (2019) Gastrointestinal malabsorption of thyroxine. Endocrine Reviews 40: 118-136.

10. Wenzel KW, Kirschsieper HE (1977) Aspects of the absorption of oral L-thyroxine in normal man. Metabolism 26: 1-8. [Crossref]

11. FDA (2017) LEVO-T (levothyroxine sodium) tablets, for oral use. Neolpharma, Inc. Caguas, Puerto Rico 00725.

12. Dickerson RN, Maish GO, Minard G, Brown R (2010) Clinical relevancy of the levothyroxine-continuous enteral nutritional interaction. Nutr Clin Pract 25: 646-6562.

13. Manessis A, Lascher S, Buckberg P, Darmody T, Yen V, et al. (2008) Quantifying amount of adsorption of levothyroxine by percutaneous endoscopic gastrostomy tube. J parenteral Enteral Nutrition 32: 107-200.

14. Alba P, Mitre N, Feldt Max (2016) More than one way to skin a thyroid. Managing pediatric hypothyroidism with weekly intramuscular levothyroxine: a case series. $J$ Pediatr Endocrinol Metab 29: 745-748.

15. Eledrisi MS, SzymajdaA, Alshanti M, Urban RJ (2001) Noncompliance with medical treatmemt: pseudomalbsorption of levothyroxine. South Med J 94: 833-836.

16. Anderson L, Joseph F, Goenka N, Patel V (2009) Isolated thyroxine malabsorption treated with intramuscular thyroxine injections. Am J Med Sc 337: 150-152.

17. Gamboa MG, Saban M, Curria MI (2019) Treatment with intramuscular levothyroxine in refractory hypothyroidism. Eur Thyroid $J$ 8: 319-323.

18. Taylor PN, Tabasum A, Sanki G, Burberry D, Tennant BP, et al. (2015) Weekly intramuscular injection of levothyroxine following myxedema: a practical solution to an old crisis. Case Reports Endocrinol 169194: 1-3.

19. Peynirci H, Taskiran B, Erturk E, Sisman P, Ersoy C (2018) Is parenteral levothyroxine therapy safe in intractable hypothyroidism? J Natl Med Association 110: 245-249.

20. Groener JB, Lehnhoff D, Piel D, Nawroth PP, Schanz J, et al. (2013) Subcutaneous application of levothyroxine as successful treatment option in a patient with malabsorption. Am J Case Rep 14: 48-51.

21. Pirola J, Daffini L Gandossi E, Lombardi D, Formenti A, et al. (2014) Comparison between liquid and tablet levothyroxine formulations in patients treated through enteral feeding tube. J Endocrinol Invest 37: 583-587.

Copyright: (C2020 Mikhail N. This is an open-access article distributed under the terms of the Creative Commons Attribution License, which permits unrestricted use, distribution, and reproduction in any medium, provided the original author and source are credited. 